\title{
A Web Interface for Antibiotic Prescription Recommendations in Primary Care: User-Centered Design Approach
}

\author{
Ronni Madar $^{1}, \mathrm{MD}$; Adrien Ugon ${ }^{2,3}, \mathrm{PhD}$; Damir Ivankovic ${ }^{4}, \mathrm{MD}$; Rosy Tsopra ${ }^{1,5,6,7}, \mathrm{MD}, \mathrm{PhD}$ \\ ${ }^{1}$ Université Sorbonne Paris Nord, Bobigny, France \\ ${ }^{2}$ ESIEE-Paris, Noisy-le-Grand, France \\ ${ }^{3}$ Laboratoire d'Informatique de Paris 6, CNRS, Sorbonne Université, Paris, France \\ ${ }^{4}$ Department of Public and Occupational Health, Amsterdam Public Health Research Institute, Amsterdam UMC, University of Amsterdam, Amsterdam, \\ Netherlands \\ ${ }^{5}$ Inserm, Université de Paris, Sorbonne Université, Centre de Recherche des Cordeliers, Information Sciences to support Personalized Medicine, Paris, \\ France \\ ${ }^{6}$ Inria Paris, Paris, France \\ ${ }^{7}$ Department of Medical Informatics, Hôpital Européen Georges-Pompidou, Assistance Publique - Hôpitaux de Paris, Paris, France
}

\section{Corresponding Author:}

Rosy Tsopra, MD, PhD

Inserm, Université de Paris, Sorbonne Université, Centre de Recherche des Cordeliers, Information Sciences to support Personalized Medicine

15 rue de l'école de médecine

Paris, 75006

France

Phone: 3356092167

Email: rosy.tsopra@nhs.net

\section{Abstract}

Background: Antibiotic misuse is a serious public health problem worldwide. National health authorities release clinical practice guidelines (CPGs) to guide general practitioners (GPs) in their choice of antibiotics. However, despite the large-scale dissemination of CPGs, GPs continue to prescribe antibiotics that are not recommended as first-line treatments. This nonadherence to recommendations may be due to GPs misunderstanding the CPGs. A web interface displaying antibiotic prescription recommendations and their justifications could help to improve the comprehensibility and readability of CPGs, thereby increasing the adoption of recommendations regarding antibiotic treatment.

Objective: This study aims to design and evaluate a web interface for antibiotic prescription displaying both the recommended antibiotics and their justifications in the form of antibiotic properties.

Methods: A web interface was designed according to the same principles as e-commerce interfaces and was assessed by 117 GPs. These GPs were asked to answer 17 questions relating to the usefulness, user-friendliness, and comprehensibility and readability of the interface, and their satisfaction with it. Responses were recorded on a 4-point Likert scale (ranging from "absolutely disagree" to "absolutely agree"). At the end of the evaluation, the GPs were allowed to provide optional, additional free comments.

Results: The antibiotic prescription web interface consists of three main sections: a clinical summary section, a filter section, and a recommended antibiotics section. The majority of GPs appreciated the clinical summary (90/117, 76.9\%) and filter (98/117, $83.8 \%$ ) sections, whereas $48.7 \%$ (57/117) of them reported difficulty reading some of the icons in the recommended antibiotics section. Overall, 82.9\% (97/117) of GPs found the display of drug properties useful, and 65.8\% (77/117) reported that the web interface improved their understanding of CPG recommendations.

Conclusions: The web interface displaying antibiotic recommendations and their properties can help doctors understand the rationale underlying CPG recommendations regarding antibiotic treatment, but further improvements are required before its implementation into a clinical decision support system.

(J Med Internet Res 2021;23(6):e25741) doi: 10.2196/25741 


\section{KEYWORDS}

clinical decision support system; visualization; usability; clinical practice guidelines; antibiotic; primary care

\section{Introduction}

Antibiotic misuse is a serious public health problem worldwide $[1,2]$. It exposes patients to the risk of adverse effects and complications, including death $[3,4]$, as well as bacterial resistance [5]. Most antibiotic prescriptions are made in primary care settings. In this context, the choice of antibiotic is usually empiric (ie, without identification of the causative bacterium) and depends on various microbiological, epidemiological, pharmacological, patient condition-, and general practitioner (GP)-related factors [6].

National health authorities release clinical practice guidelines (CPGs) to guide GPs in their choice of antibiotics. CPGs contain evidence-based recommendations from a group of experts based on scientific publications. However, despite the large-scale diffusion of CPGs, GPs continue to prescribe antibiotics that are not recommended for first-line treatment (eg, broad-spectrum antibiotics) $[7,8]$. This noncompliance with recommendations may be due to the GPs misunderstanding the CPGs or their lack of confidence in these guidelines $[9,10]$. Indeed, it has been shown that GPs are suspicious of the content of CPGs; they believe that the recommendations are driven by economic issues rather than a desire to improve patient care and that there is a lack of evidence to support the recommendations [11]. They also find the guidelines unclear, ambiguous, incomplete, complex, and unusable in clinical practice [11].

An antibiotic prescription web interface displaying not only recommendations of antibiotics but also their justifications could help improve the GPs' comprehensibility and readability of CPGs, thereby increasing the adoption of recommendations regarding antibiotic treatment. The justifications for antibiotic recommendations can be found within CPG documents, but they are often lost or hidden in large amounts of text [12,13]. A qualitative analysis of CPGs [12,13] for antibiotic treatment showed that these justifications were based on antibiotic properties [14,15]. For example, fosfomycin trometamol is recommended for the treatment of uncomplicated cystitis because of the following properties: short-duration protocol, few side effects, and little collateral damage. The display of antibiotic properties in an easily accessible and understandable manner could therefore help improve the comprehensibility and readability of CPGs for GPs, thereby increasing the chances of them successfully adopting those recommendations.

It is not easy to display the recommended antibiotics and their properties in a readily usable interface $[16,17]$. In the context of antibiotic treatment, several kinds of interface have been used, including textual formats [18,19], tables [19], diagrams [20], hypertextual links [21], and tick boxes [18]. Outside the domain of medicine, e-commerce interfaces (such as those used by e-commerce organizations like Booking, eBay, and Amazon) are widespread and make it possible for consumers to compare particular parameters between products. However, surprisingly, interfaces of this type are rarely used in the medical domain.
Such e-commerce interfaces could be an effective way of displaying both antibiotics and their properties.

In this study, we aim to (1) design a web interface for antibiotic prescription presenting recommendations and justifications, in the form of an e-commerce interface displaying antibiotics and their properties, and (2) evaluate the readability and utility of this interface for improving the GPs' comprehension of CPGs.

\section{Methods}

\section{Interface Design}

The elements involved in medical decision-making for antibiotic prescription have been previously identified based on analyses of clinical guidelines [14] and clinical expertise [6].

The best way to organize these elements into the proposed web interface was determined by reviewing and analyzing the content of the following:

1. Health care interfaces: However, no interface with a design similar to that of an e-commerce interface was retrieved.

2. Several well-known e-commerce websites for booking trips or hotels and web-based stores: A panel of websites were reviewed and the interface of four selected e-commerce websites (ie, Booking, Amazon, Tripadvisor, and LeBonCoin) were analyzed in greater detail. This analysis revealed that these interfaces contained three common main sections: a summary section, a result section, and a filter section (Figure 1). The same partitioned sections were then used to organize the elements involved in medical decision-making and to design the web interface.

The summary section of e-commerce interfaces usually displays the search criteria entered by the user when searching for a product (eg, "hotels in Paris from 21/12/2020 to 26/12/2020"). In our web interface, the elements "patient profiles" and "diseases" (eg, adult pharyngitis) were considered as search criteria.

The filter section of e-commerce interfaces usually displays optional parameters that users can click to filter the products selected in response to the initial search criteria (eg, hotel price). In our web interface, elements relating to certain generic patient conditions that are taken into account during drug prescription (eg, renal failure) were considered as optional parameters.

Finally, the result section of e-commerce interfaces usually displays the products recommended after both the search criteria and the optional parameters entered by the user have been taken into account. The characteristics of the products are usually also displayed in the form of icons to facilitate product comparison (eg, an icon for a swimming pool). In the web interface, the elements "antibiotic" and "antibiotic properties" were considered as products and characteristics, respectively. The antibiotics recommended in CPGs and the properties used by CPG experts to make those recommendations would then be displayed. A previous study identified seven preference properties (eg, "convenient protocol") that are currently used by experts for 
making recommendations [14]. Antibiotics satisfying these properties are preferred over others, depending on the clinical situation (eg, in women with uncomplicated cystitis, fosfomycin trometamol is preferred over other antibiotics because it has the property "convenient protocol"). For each preference property, two junior doctors reviewed the icon web sites and designed personalized icons using Inkscape. The seven preference properties, as described by CPG experts, are shown along with the representative icons in Table 1.

Figure 1. Basic wireframe of e-commerce interfaces compartmentalized into sections.

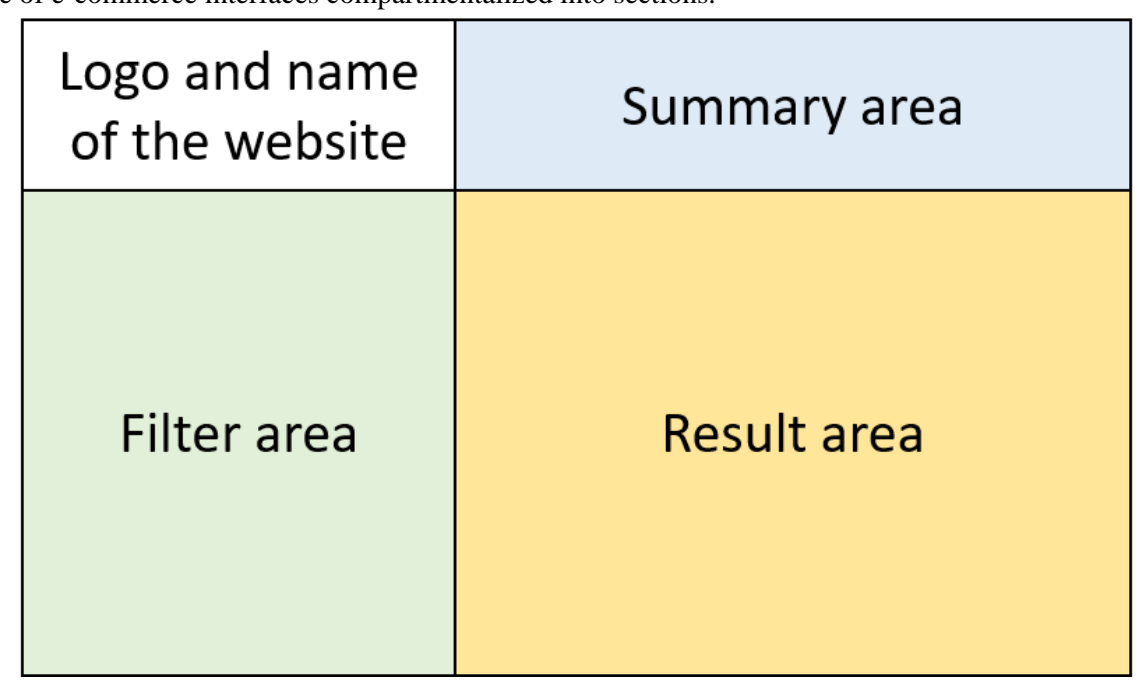

Table 1. Icons used for displaying antibiotic properties.

\begin{tabular}{|c|c|c|c|}
\hline Preference property & Definition $^{\mathrm{a}}$ & Icon description & Icon \\
\hline Convenient protocol & $\begin{array}{l}\text { If the antibiotic is prescribed orally and for less than } \mathrm{Z} \\
\text { days } \mathrm{b}\end{array}$ & Symbolized by a capsule placed on a hand & 8 \\
\hline $\begin{array}{l}\text { Absence of serious and } \\
\text { frequent side effects }\end{array}$ & $\begin{array}{l}\text { If there is no risk of serious side effects and the frequency } \\
\text { of side effects is sufficiently low to allow prescription }\end{array}$ & $\begin{array}{l}\text { Symbolized by a face with skin rash with an inter- } \\
\text { dictory stroke }\end{array}$ & 8 \\
\hline Nonprecious class & $\begin{array}{l}\text { If the antibiotic does not belong to a class of drugs that } \\
\text { must be preserved for more serious infections }\end{array}$ & $\begin{array}{l}\text { Symbolized by a diamond with an interdictory } \\
\text { stroke }\end{array}$ & $\varnothing$ \\
\hline $\begin{array}{l}\text { Narrow antibacterial } \\
\text { spectrum }\end{array}$ & $\begin{array}{l}\text { If the antibiotic is described as having a narrow antibacte- } \\
\text { rial spectrum }\end{array}$ & Symbolized by mass spectrum graph & (iin) \\
\hline $\begin{array}{l}\text { Low level of ecological } \\
\text { adverse effects }\end{array}$ & $\begin{array}{l}\text { If the antibiotic is described as having a low risk of promot- } \\
\text { ing bacterial resistance }\end{array}$ & Symbolized by a recycling icon & 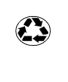 \\
\hline High level of efficacy & $\begin{array}{l}\text { If the antibiotic is described as very effective (eg, high } \\
\text { clinical cure percentage) }\end{array}$ & $\begin{array}{l}\text { Symbolized by brachial biceps with a boxing } \\
\text { glove }\end{array}$ & (3) \\
\hline Acceptable taste & $\begin{array}{l}\text { If the antibiotic is described as having an acceptable taste } \\
\text { for oral administration }\end{array}$ & Symbolized by a face with tongue emoji & $\bullet$ \\
\hline
\end{tabular}

${ }^{\mathrm{a}}$ Expert definitions within clinical practice guidelines. Source: [14].

${ }^{b_{Z}} \mathrm{Z}$ : the period depends on the clinical situation.

\section{Interface Assessment}

The utility of the interface for improving GPs' comprehension of CPGs and their readability was evaluated using a questionnaire tailored to the study.

\section{GP Recruitment}

GPs were contacted via emails sent to medical networks in the Île-de-France region (including Paris) and by word of mouth, between March 25 and April 25, 2018. A reminder was sent 15 days after the first contact was made. For inclusion in the study, GPs had to be in training or practicing in primary care. The evaluation was voluntary and anonymous.

\section{Study Design}

A web-based evaluation was carried in three steps. First, the participating GPs were asked to answer five sociodemographic questions. Their responses were rendered anonymous. Next, the GPs were asked to use the web interface for the use case "young adult woman with uncomplicated pyelonephritis." The information displayed on the web interface was derived from a knowledge base describing 11 infectious diseases, 50 antibiotics, and 21 patient profiles, constructed based on French CPGs and clinical expertise (a description of this knowledge base is available in the literature [14]). Then, the GPs were asked to answer 17 questions relating to usefulness (3 questions), user-friendliness (3 questions), satisfaction (3 questions) and 
comprehension (8 questions). The responses were recorded on a 4-point Likert scale (ie, "absolutely disagree," "tend to disagree," "tend to agree," and "absolutely agree"). At the end of the evaluation, GPs were provided with an opportunity to write optional free comments.

\section{Results}

\section{Web Interface for Antibiotic Prescription}

The web interface for antibiotic prescription was divided into three main sections, as in most e-commerce websites (Figure 2):

1. The clinical summary section, located at the top of the interface, displays a short summary of the clinical situation defined by both the disease and the profile of the patient (eg, sex, age).
2. The filter section, located at the top left of the interface, can be used to filter the recommended drugs according to patient-specific conditions such as drug allergies, renal failure, pregnancy, and/or breastfeeding.

3. The recommended antibiotics section, located in the center of the interface, displays the recommended drugs, with justifications in the form of drug properties. These preference properties are represented by seven icons. Each icon is shown in a different color, as follows: green, if the recommended antibiotic satisfies the property; red, if the recommended antibiotic does not satisfy the property; and grey, if no information is available. For each recommended drug, the recommendation rank is displayed with a numbered thumbs-up icon, as per the CPGs.

4. The legend located at the bottom of the interface highlights the icons used in the recommended antibiotics section and displays hypertextual links to the original CPGs.

Figure 2. Web interface for antibiotic prescription displaying recommended drugs and their properties.

Clinical situation:
Gender: Woman Age: 28 years old
Disease: Uncomplicated acute pyelonephritis without treatment by
fluoroquinolones during the six previous months
fluoroquinolones during the six previous months

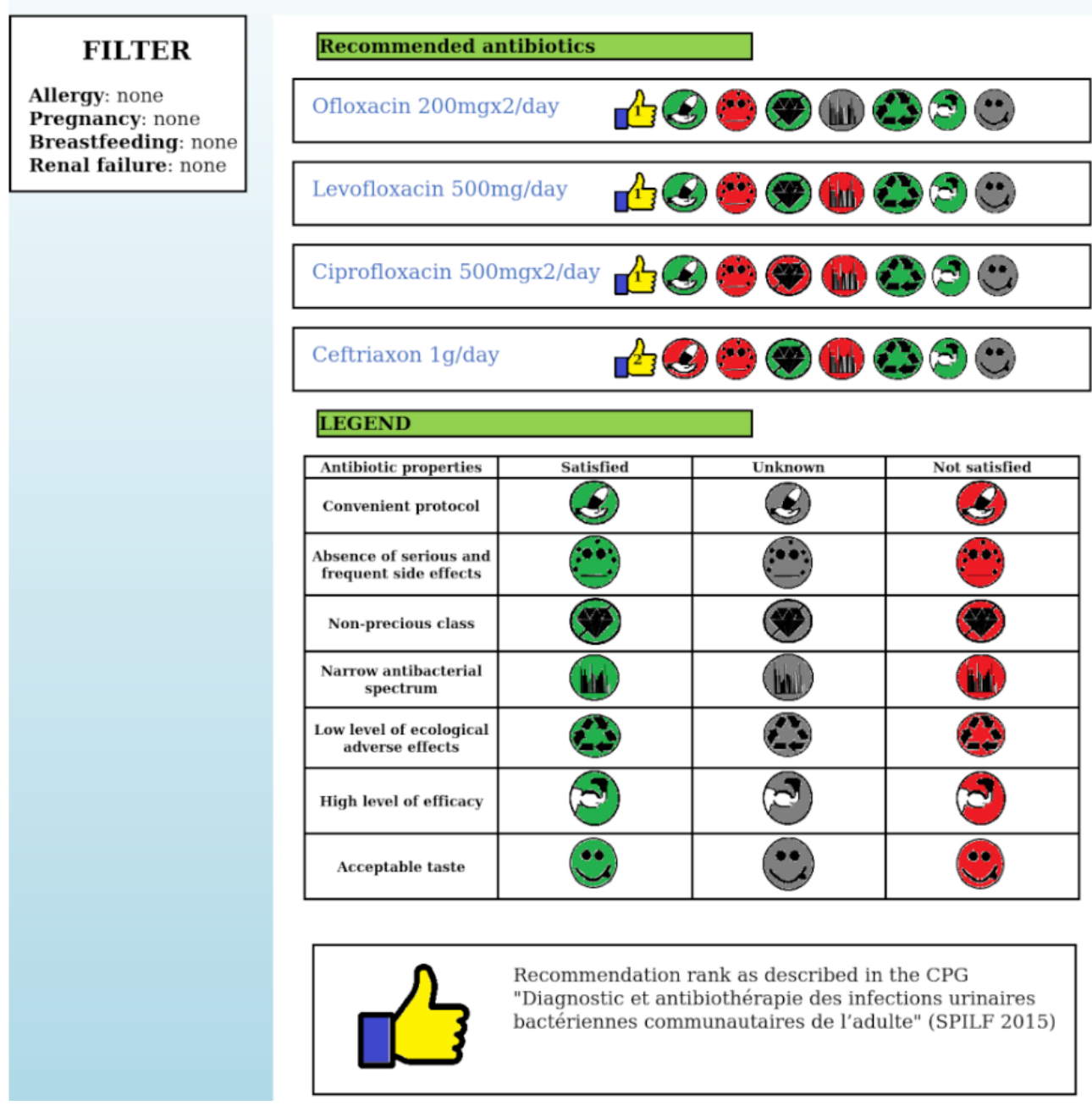


Evaluation of the Antibiotic Prescription Web Interface

\section{Characteristics of Participating GPs}

Given the opportunistic nature of the recruitment method used, it is difficult to estimate accurately how many GPs received the invitation email. The number of GPs contacted was estimated to range between 850 and 880 .
In total, 117 GPs working within distinct GP surgeries accepted the invitation and assessed the web interface. More than half (73/117, 62.4\%) were female. More than three-fourths (104/117, $89.0 \%$ ) were under 40 years of age and had been in practice for less than 10 years. More than half $(77 / 117,65.8 \%)$ were working in private practice (Table 2).

Table 2. Sociodemographic characteristics of the general practitioners (GPs) (N=117).

\begin{tabular}{|c|c|}
\hline Characteristic & Value, $\mathrm{n}(\%)$ \\
\hline \multicolumn{2}{|l|}{ Sex } \\
\hline Female & $73(62.4)$ \\
\hline Male & $44(37.6)$ \\
\hline \multicolumn{2}{|l|}{ Age (years) } \\
\hline $20-30$ & $42(36.0)$ \\
\hline $30-40$ & $62(53.0)$ \\
\hline $40-50$ & $7(6.0)$ \\
\hline $50-60$ & $3(2.5)$ \\
\hline$>60$ & $3(2.5)$ \\
\hline \multicolumn{2}{|l|}{ Professional status } \\
\hline GP with an MD thesis & $74(63.3)$ \\
\hline GP without an MD thesis & $39(33.3)$ \\
\hline GP in training & $4(3.4)$ \\
\hline \multicolumn{2}{|l|}{ Time in practice (years) } \\
\hline$<5$ & $81(69.2)$ \\
\hline $5-10$ & $20(17.1)$ \\
\hline $10-20$ & $10(8.5)$ \\
\hline$>20$ & $6(5.2)$ \\
\hline \multicolumn{2}{|l|}{ Practice type } \\
\hline Private & $77(65.8)$ \\
\hline Salaried & $15(12.8)$ \\
\hline Mixed & $25(21.4)$ \\
\hline
\end{tabular}

\section{Satisfaction, Usefulness, Comprehensibility, and Readability of the Web Interface}

Overall, 82.9\% (97/117) of GPs found the display of drug properties useful (95\% CI 76-90); 65.8\% (77/117) reported that the interface improved their understanding of CPG recommendations (95\% CI 57-74), and 59.8\% (70/117) considered the interface useful for clinical practice $(95 \% \mathrm{CI}$ 51-69), as shown in Figure 3.

Only 54.7\% (64/117) of all GPs were satisfied with the global interface (95\% CI 46-64), probably because of dissatisfaction with some of the icons. Indeed, the majority of GPs appreciated the clinical summary $(90 / 117,76.9 \%)$ and filter $(98 / 117,83.8 \%)$ sections, whereas $48.7 \%$ (57/117) of them reported difficulties understanding some of the icons (Figure 3).

Five of the eight icons were considered sufficiently readable. The icons for recommended rank, ecological adverse effects, and taste were considered easily understandable by more than $80 \%$ of GPs; both the precious class and the side effects icons were considered comprehensible by more than $60 \%$ of all GPs. By contrast, three icons were not sufficiently readable; icons for antibacterial spectrum and convenient protocol were considered poorly understandable by nearly half the GPs and that for efficacy level was considered poorly understandable by about $84 \%$ of GPs (Figure 3). 
Figure 3. Satisfaction, usefulness, readability, and comprehensibility of the web interface according to general practitioners. In the questionnaire, each item was turned into an affirmative sentence to be graded on a 4-point Likert scale ranging from "absolutely disagree" to "absolutely agree" (eg, the item "Utility of displaying drug properties" was converted to the statement "I found the display of drug properties useful" and this affirmation was then graded).

INTERFACE USEFULNESS

Utility of displaying drug properties

Utility for a better comprehension of CPG recommendations

Utility for clinical practice

INTERFACE USER-FRIENDLINESS

Easy to use

Easy to read

Easy to read icons

INTERFACE SATISFACTION

General satisfaction

Satisfaction with the clinical summary area

Satisfaction with the filter area

EASY COMPREHENSION OF ICONS

Recommended rank

Low level of ecological adverse effects

Acceptable taste

Non-precious class

Absence of serious and frequent side effects

Narrow antibacterial spectrum

Convenient protocol

High level of efficacy

\section{Areas for Improvement}

Some GPs said that they found the web interface interesting but that it could take time for them to get familiar with it. They suggested several areas for improvement (Table 3).

For the clinical summary section, GPs suggested displaying more details about the probable causal microbes, patient history, treatment, and signs of gravity. For the filter section, they suggested adding filters for hepatic conditions and galenic forms. Regarding the recommended antibiotics section, the GPs thought it included too much information and needed to be simplified to improve readability. For example, some GPs said that only the most important properties should be displayed and that other properties should be hidden and accessible only on request (eg,

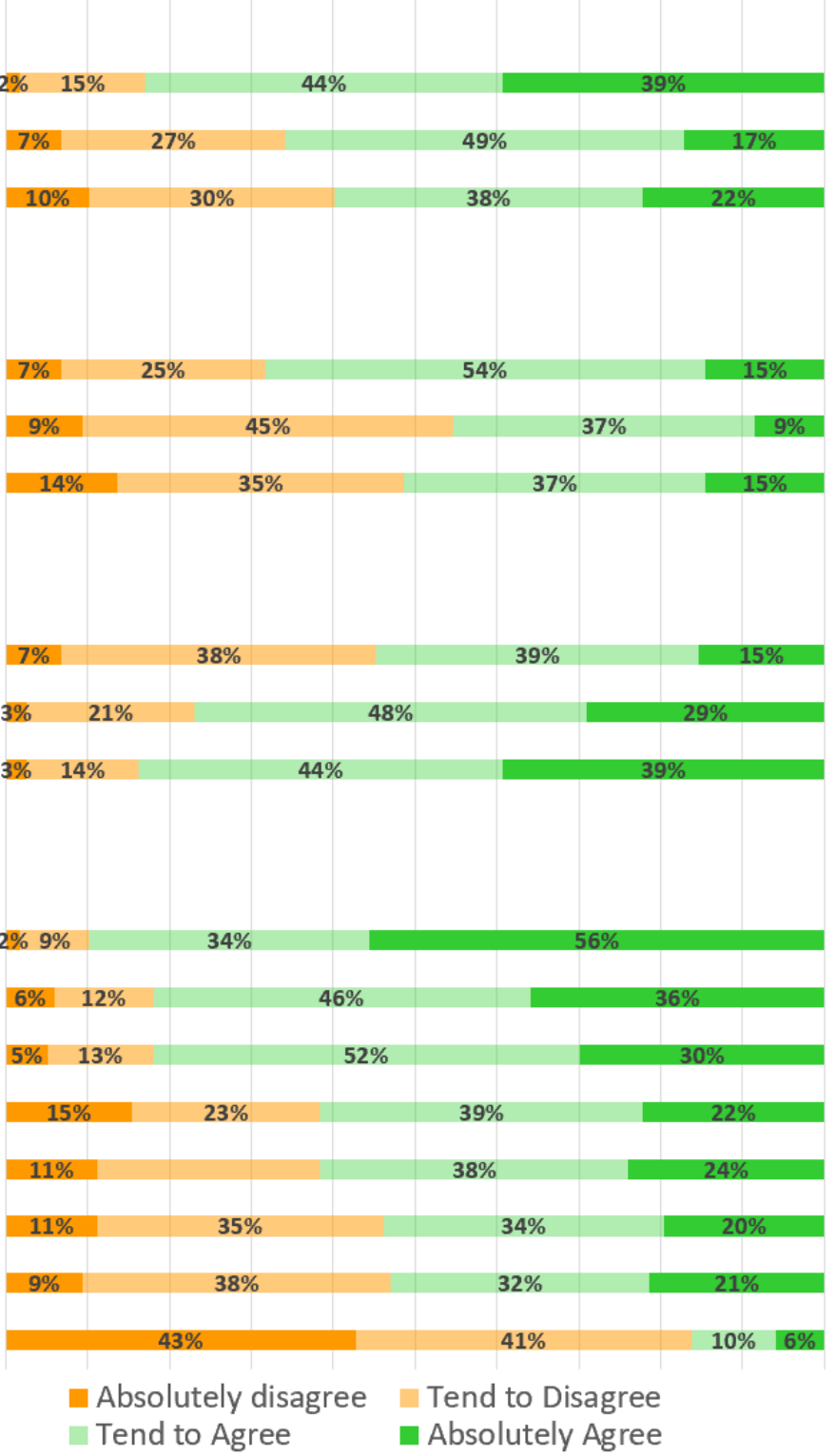

nonprecious class, efficacy level, and taste). Surprisingly, some GPs reported that some properties were not important for the choice of antibiotic, whereas these properties were used by CPG experts in the formulation of recommendations (eg, ecological adverse effects, activity spectrum, antibiotic taste). Other GPs also had doubts about the nonprecious class property because they did not understand what this meant. Conversely, other GPs suggested including additional properties such as drug cost, drug-drug interactions, and contraindications. Some others said that some of the icons were not sufficiently intuitive and required revision. They suggested, for example, replacing the efficacy level by a graduated scale, speedometer, or weapon symbol. Finally, some GPs said that they thought the web interface could be useful for shared decision-making with patients. 
Table 3. Areas for improvement extracted by analysis of free comments by general practitioners (GPs) (N=117).

\begin{tabular}{l} 
Interface section and suggested improvement \\
\hline Clinical summary \\
Add more information about patient history and current treatment \\
Add more information about clinical signs of gravity \\
Add details about the suspected causal microbes \\
Filter \\
Add hepatic condition filter \\
Add galenic form preference (eg, syrup, pill) \\
Recommended antibiotics \\
Improve readability \\
Add some properties (eg, duration, cost) \\
Specify important patient contraindications for each antibiotic \\
Specify drug-drug interactions \\
DiSCUSSiOn
\end{tabular}

\section{Principal Findings}

An interface for antibiotic prescription displaying the recommendations and their justifications was designed and assessed. The web interface was divided into three main sections: a clinical summary section, a filter section, and a recommended antibiotics section enlisting recommended antibiotics and their properties displayed as icons. Overall, $82.9 \%$ of participating GPs found the display of drug properties useful, and $65.8 \%$ of them reported that the interface helped to improve their understanding of CPG recommendations. Nevertheless, the interface requires further improvement before its implementation in a clinical decision support system (CDSS).

\section{Limitations}

\section{Interface Design}

\section{Icon Design}

Despite $82.9 \%$ of the GPs reporting that they found the display of antibiotic properties useful, $48.7 \%$ reported difficulty in reading the corresponding icons. Starren et al [22] described five kinds of presentation for displaying medical data (ie, table, list, graph, generated text, and icon). We believed that icons were the most suitable presentation for displaying the antibiotic properties because they are small pictorial symbols that are particularly well adapted for displaying qualitative data within computer interfaces [22]. Furthermore, they are already widely used for displaying medical data such as for medication administration or patient events [22]. Iconic languages [23-25] have even been developed in the medical domain, such as the Visualisation des Connaissances Médicales (Visualization of Medical Knowledge [VCM]) language [25,26], which is used to represent signs, diseases, physiological states, life habits, and drugs. However, as there were no existing icons for representing antibiotic properties, the icons for this interface were designed by ourselves. Designing unambiguous icons for displaying precise concepts, such as "low level of ecological adverse effects" or "narrow antibacterial spectrum" was not an easy
GP, n $(\%)$

$9(7.7)$

$31(26.5)$

$8(6.8)$

$2(1.7)$

$3(2.6)$

task, and it can take time for the GPs to become familiar with these icons. In our study, GPs discovered the icons for the first time during the evaluation period, with no prior tutorial or training, potentially accounting for their lack of satisfaction with the existing icons. The next step will be improving the design of some icons in accordance with the suggestions made by the GPs participating in this study (eg, "efficacy level" could be represented by a graduated scale). A tutorial and interactive information bubble will also be added to improve the readability of icons.

\section{Missing Elements}

The interface displayed the recommendations and the elements required for antibiotic prescription according to the experts writing CPGs. However, the qualitative analysis of the free comments highlighted the following: (1) some properties were considered important by CPG experts but not by GPs (eg, CPG experts considered antibiotic taste to be important for improving treatment adherence, whereas this was not the case for all GPs); (2) GPs considered other properties not mentioned in CPGs to be important (eg, some GPs reported needing to visualize drug interactions, which are seldom dealt with in CPGs); and (3) some properties are currently used by CPGs experts but are not understood by GPs (eg, the property nonprecious class). This gap between real-life practice and writing CPGs should be considered when designing CDSS interfaces. Thus, interfaces should also include the properties used by GPs in real-life practice, even if the evidence for their use is poor or not given in CPGs. For example, with regard to antibiotic prescription, Krishnakumar et al [6] developed a model of the rationale used by GPs for antibiotic choice. Some of the factors included in this model, such as drug pharmacokinetics, marketing authorization, and drug cost, will be included in the web interface in the future.

\section{Interface Evaluation}

The participating GPs were recruited via emails sent to medical networks and by word of mouth. This mode of recruitment was chosen because it is faster and cheaper than traditional approaches $[27,28]$. However, it may have introduced a selective 
participation bias [28] (eg, by selecting GPs keen on the use of new technologies). This bias was limited by using large mailing lists (>850 GPs), including GPs working in various health care centers, from a large French region (including Paris). The readability of the interface and its utility for improving GPs' comprehension of CPGs were also evaluated. Assessments of readability and comprehensibility are part of the software lifecycle and may prevent serious usability problems, which often occur during the design of new technologies [29]. Early testing makes it possible to identify serious issues and to improve the interface before its implementation in a CDSS.

\section{Comparison With Previous Work}

\section{Comparison With Other Drug Comparison Interfaces}

Other types of interfaces have been developed for comparing drugs in medical domains. With regard to Dopamine [30], for instance, double-entry tables were used to compare the contraindications and side effects of drugs. More sophisticated tables, including the possibilities of overlapping data and interactions, have also been developed, such as Twinlist [31] for medication reconciliation or rainbow boxes [32,33] for comparing drug information such as contraindications or side effects. Rainbow boxes were previously adapted for use in antibiotic prescription [34]; the resulting rainbow interface was perceived as easy to read for $27.5 \%-64 \%$ of GPs, depending on the clinical situation. However, as smartphones are increasingly being used by medical doctors for learning, information retrieval, and/or clinical decision support [35-38], it is important to consider interfaces more suitable for use with a smartphone. Tabular representations take up a large amount of space and are therefore more suitable for computer interfaces $[39,40]$. Here, an e-commerce interface adaptable for smartphones was designed as a means of overcoming this limitation. Graphs have also been used for drug comparisons, such as Rxplore [41] for the rapid review of potential drug events caused by drugs and Network graph [42] for chemotherapy treatment. However, in these cases, graphical representations were interesting because of the need to add quantitative information such as the results of clinical trials [42]. As antibiotic properties are qualitative data, graphical representations were not considered appropriate for this situation.

\section{Comparison With Other Antibiotic Prescription Interfaces}

Other interfaces have been developed for the empiric prescription of antibiotics in primary care, for example, IAAP Smart phone [43], ARI Smart Form [44], and ABX TRIP [21] for acute respiratory infections. These interfaces display antibiotic recommendations without their justifications-that is, only the recommended antibiotics are displayed in a textual format without their properties. This type of presentation suffers from "the black box effect" [45] and may make GPs passive in their decision-making process, simply accepting the decision suggested by the CDSS. GPs may also be suspicious of the recommendations due to a lack of understanding of the suggestions made by the CDSS. In our proposed interface, drug properties were displayed to involve GPs in the decision process. This improves their understanding of the underlying reasons for recommendations and enables them to compare the advantages and disadvantages of the recommended antibiotics. Preserving GP autonomy is an important factor to be considered when trying to increase the chances of CDSS being successfully adopted [46].

\section{Conclusions}

A web interface for antibiotic prescription presenting drug recommendations and their justifications was designed following the basic framework of an e-commerce interface. The justifications of CPG recommendations were displayed in the form of antibiotic properties, which was considered useful by more than three-fourths of GPs and helpful for understanding CPGs by two-thirds of GPs evaluating the interface. Further improvements are required before the implementation of this interface in a CDSS.

\section{Acknowledgments}

We thank the GPs for taking time to participate in this study despite their heavy workload. This study was funded by the Agence Nationale de Sécurité du Médicament et des Produits de santé (ANSM). APP 2016 - RaMiPA Project (Raisonner pour Mieux Prescrire les Antibiotiques or Reasoning for better antibiotic prescription) led by RT.

\section{Authors' Contributions}

RT led the project. RM and RT designed the study. RM, AU, DI, and RT designed the web interface.

RM and RT analyzed and interpreted the data. RT wrote the manuscript. All authors critically edited and approve the final version of the manuscript.

\section{Conflicts of Interest}

None declared.

\section{References}

1. Olesen SW, Barnett ML, MacFadden DR, Lipsitch M, Grad YH. Trends in outpatient antibiotic use and prescribing practice among US older adults, 2011-15: observational study. BMJ 2018 Jul 27;362:k3155 [FREE Full text] [doi: 10.1136/bmj.k3155] [Medline: 30054353] 
2. van Houten CB, Cohen A, Engelhard D, Hays JP, Karlsson R, Moore E, et al. Antibiotic misuse in respiratory tract infections in children and adults-a prospective, multicentre study (TAILORED Treatment). Eur J Clin Microbiol Infect Dis 2019 Mar;38(3):505-514 [FREE Full text] [doi: 10.1007/s10096-018-03454-2] [Medline: $\underline{30707378]}$

3. Tamma PD, Avdic E, Li DX, Dzintars K, Cosgrove SE. Association of adverse events with antibiotic use in hospitalized patients. JAMA Intern Med 2017 Sep 01;177(9):1308-1315 [FREE Full text] [doi: 10.1001/jamainternmed.2017.1938] [Medline: 28604925]

4. Marquet K, Liesenborgs A, Bergs J, Vleugels A, Claes N. Incidence and outcome of inappropriate in-hospital empiric antibiotics for severe infection: a systematic review and meta-analysis. Crit Care 2015 Feb 16;19:63 [FREE Full text] [doi: 10.1186/s13054-015-0795-y] [Medline: 25888181]

5. Ventola CL. The antibiotic resistance crisis: part 1: causes and threats. P T 2015 Apr;40(4):277-283 [FREE Full text] [Medline: 25859123]

6. Krishnakumar J, Tsopra R. What rationale do GPs use to choose a particular antibiotic for a specific clinical situation? BMC Fam Pract 2019 Dec 20;20(1):178 [FREE Full text] [doi: 10.1186/s12875-019-1068-7] [Medline: 31862003]

7. Shively NR, Buehrle DJ, Clancy CJ, Decker BK. Prevalence of inappropriate antibiotic prescribing in primary care clinics within a Veterans Affairs health care system. Antimicrob Agents Chemother 2018 Aug;62(8):1-7. [doi: 10.1128/aac.00337-18]

8. Marc C, Vrignaud B, Levieux K, Robine A, Guen CG, Launay E. Inappropriate prescription of antibiotics in pediatric practice: analysis of the prescriptions in primary care. J Child Health Care 2016 Dec;20(4):530-536. [doi: 10.1177/1367493516643421] [Medline: 27091956]

9. Cabana MD, Rand CS, Powe NR, Wu AW, Wilson MH, Abboud PA, et al. Why don't physicians follow clinical practice guidelines? A framework for improvement. JAMA 1999 Oct 20;282(15):1458-1465. [doi: 10.1001/jama.282.15.1458] [Medline: 10535437$]$

10. Correa VC, Lugo-Agudelo LH, Aguirre-Acevedo DC, Contreras JAP, Borrero AMP, Patiño-Lugo DF, et al. Individual, health system, and contextual barriers and facilitators for the implementation of clinical practice guidelines: a systematic metareview. Health Res Policy Syst 2020 Jun 29;18(1):74 [FREE Full text] [doi: 10.1186/s12961-020-00588-8] [Medline: 32600417]

11. Bierbaum M, Rapport F, Arnolda G, Nic Giolla Easpaig B, Lamprell K, Hutchinson K, et al. Clinicians' attitudes and perceived barriers and facilitators to cancer treatment clinical practice guideline adherence: a systematic review of qualitative and quantitative literature. Implement Sci 2020 May 27;15(1):39 [FREE Full text] [doi: 10.1186/s13012-020-00991-3] [Medline: 32460797]

12. Tsopra R, Venot A, Duclos C. Towards evidence-based CDSSs implementing the medical reasoning contained in CPGs: application to antibiotic prescription. Stud Health Technol Inform 2014;205:13-17. [Medline: 25160136]

13. Tsopra R, Venot A, Duclos C. An algorithm using twelve properties of antibiotics to find the recommended antibiotics, as in CPGs. AMIA Annu Symp Proc 2014;2014:1115-1124 [FREE Full text] [Medline: 25954422]

14. Tsopra R, Lamy J, Sedki K. Using preference learning for detecting inconsistencies in clinical practice guidelines: Methods and application to antibiotherapy. Artif Intell Med 2018 Jul;89:24-33. [doi: 10.1016/j.artmed.2018.04.013] [Medline: 29776758]

15. Lamy J, Sedki K, Tsopra R. Explainable decision support through the learning and visualization of preferences from a formal ontology of antibiotic treatments. J Biomed Inform 2020 Apr;104:103407. [doi: 10.1016/j.jbi.2020.103407] [Medline: $\underline{32156641]}$

16. Sutton RT, Pincock D, Baumgart DC, Sadowski DC, Fedorak RN, Kroeker KI. An overview of clinical decision support systems: benefits, risks, and strategies for success. NPJ Digit Med 2020;3:17 [FREE Full text] [doi: 10.1038/s41746-020-0221-y] [Medline: 32047862]

17. Miller K, Mosby D, Capan M, Kowalski R, Ratwani R, Noaiseh Y, et al. Interface, information, interaction: a narrative review of design and functional requirements for clinical decision support. J Am Med Inform Assoc 2018 May 01;25(5):585-592. [doi: 10.1093/jamia/ocx118] [Medline: 29126196]

18. Shen Y, Yuan K, Chen D, Colloc J, Yang M, Li Y, et al. An ontology-driven clinical decision support system (IDDAP) for infectious disease diagnosis and antibiotic prescription. Artif Intell Med 2018 Mar;86:20-32. [doi: 10.1016/j.artmed.2018.01.003] [Medline: 29433958]

19. Akhloufi H, Verhaegh SJC, Jaspers MWM, Melles DC, van der Sijs H, Verbon A. A usability study to improve a clinical decision support system for the prescription of antibiotic drugs. PLoS One 2019;14(9):e0223073 [FREE Full text] [doi: 10.1371/journal.pone.0223073] [Medline: 31553785]

20. Paul M, Andreassen S, Tacconelli E, Nielsen AD, Almanasreh N, Frank U, TREAT Study Group. Improving empirical antibiotic treatment using TREAT, a computerized decision support system: cluster randomized trial. J Antimicrob Chemother 2006 Dec;58(6):1238-1245. [doi: 10.1093/jac/dk1372] [Medline: 16998208]

21. Litvin CB, Ornstein SM, Wessell AM, Nemeth LS, Nietert PJ. Adoption of a clinical decision support system to promote judicious use of antibiotics for acute respiratory infections in primary care. Int J Med Inform 2012 Aug;81(8):521-526. [doi: 10.1016/j.ijmedinf.2012.03.002] [Medline: 22483528]

22. Starren J, Johnson SB. An object-oriented taxonomy of medical data presentations. J Am Med Inform Assoc 2000;7(1):1-20 [FREE Full text] [Medline: 10641959] 
23. Preiss B, Kaltenbach M, Zanazaka J, Echave V. Concept graphics: a language for medical knowledge. Proc Annu Symp Comput Appl Med Care 1992:515-519 [FREE Full text] [Medline: 1482928]

24. Preiss B, Echavé V, Preiss SF, Kaltenbach M. UVAL-MED a universal visual associative language for medicine. Proc Annu Symp Comput Appl Med Care 1994:262-266 [FREE Full text] [Medline: 7949931]

25. Lamy J, Duclos C, Bar-Hen A, Ouvrard P, Venot A. An iconic language for the graphical representation of medical concepts. BMC Med Inform Decis Mak 2008 Apr 24;8:16 [FREE Full text] [doi: 10.1186/1472-6947-8-16] [Medline: 18435838]

26. Lamy J, Thuy VB, Lillo-Le Louët A, Bousquet C. An iconic approach to the browsing of medical terminologies. Stud Health Technol Inform 2019 Aug 21;264:213-217. [doi: 10.3233/SHTI190214] [Medline: $\underline{31437916}$ ]

27. Ali SH, Foreman J, Capasso A, Jones AM, Tozan Y, DiClemente RJ. Social media as a recruitment platform for a nationwide online survey of COVID-19 knowledge, beliefs, and practices in the United States: methodology and feasibility analysis. BMC Med Res Methodol 2020 May 13;20(1):1-11. [doi: 10.1186/s12874-020-01011-0]

28. Heiervang E, Goodman R. Advantages and limitations of web-based surveys: evidence from a child mental health survey. Soc Psychiatry Psychiatr Epidemiol 2011 Jan;46(1):69-76. [doi: 10.1007/s00127-009-0171-9] [Medline: 19921078]

29. Islam MN, Karim MM, Inan TT, Islam AKMN. Investigating usability of mobile health applications in Bangladesh. BMC Med Inform Decis Mak 2020 Feb 03;20(1):19 [FREE Full text] [doi: 10.1186/s12911-020-1033-3] [Medline: $\underline{\text { 32013965] }}$

30. Wroe C, Solomon W, Rector A, Rogers J. DOPAMINE: a tool for visualizing clinical properties of generic drugs. 2000 Presented at: Proc Fifth Workshop Intell Data Anal Med Pharmacol IDAMAP; August 22, 2000; Germany p. 61-65.

31. Plaisant C, Wu J, Hettinger AZ, Powsner S, Shneiderman B. Novel user interface design for medication reconciliation: an evaluation of Twinlist. J Am Med Inform Assoc 2015 Mar;22(2):340-349. [doi: 10.1093/jamia/ocu021] [Medline: 25665706]

32. Lamy J, Berthelot H, Favre M, Ugon A, Duclos C, Venot A. Using visual analytics for presenting comparative information on new drugs. J Biomed Inform 2017 Jul;71:58-69 [FREE Full text] [doi: 10.1016/j.jbi.2017.04.019] [Medline: 28549568]

33. Lamy J, Tsopra R. RainBio: proportional visualization of large sets in Biology. IEEE Trans Vis Comput Graph 2020 Nov;26(11):3285-3298. [doi: 10.1109/TVCG.2019.2921544] [Medline: 31180862]

34. Tsopra R, Kinouani S, Venot A, Jaulent M, Duclos C, Lamy J. Design of a visual interface for comparing antibiotics using rainbow boxes. Stud Health Technol Inform 2017;235:529-533. [Medline: 28423849]

35. Nerminathan A, Harrison A, Phelps M, Alexander S, Scott KM. Doctors' use of mobile devices in the clinical setting: a mixed methods study. Intern Med J 2017 Dec;47(3):291-298. [doi: 10.1111/imj.13349] [Medline: 27925381]

36. Dimond R, Bullock A, Lovatt J, Stacey M. Mobile learning devices in the workplace: 'as much a part of the junior doctors' kit as a stethoscope'? BMC Med Educ 2016 Aug 17;16(1):207 [ [FREE Full text] [doi: 10.1186/s12909-016-0732-z] [Medline: 27530343]

37. Zhang C, Fan L, Chai Z, Yu C, Song J. Smartphone and medical application use among dentists in China. BMC Med Inform Decis Mak 2020 Sep 07;20(1):213 [FREE Full text] [doi: 10.1186/s12911-020-01238-3] [Medline: 32894112]

38. Maassen O, Fritsch S, Gantner J, Deffge S, Kunze J, Marx G, et al. Future mobile device usage, requirements, and expectations of physicians in German university hospitals: web-based survey. J Med Internet Res 2020 Dec 21;22(12):e23955 [FREE Full text] [doi: 10.2196/23955] [Medline: 33346735]

39. Tsopra R, Sedki K, Courtine M, Falcoff H, De Beco A, Madar R, et al. Helping GPs to extrapolate guideline recommendations to patients for whom there are no explicit recommendations, through the visualization of drug properties. The example of AntibioHelp® in bacterial diseases. J Am Med Inform Assoc 2019 Oct 01;26(10):1010-1019. [doi: 10.1093/jamia/ocz057] [Medline: 31077275]

40. Tsopra R, Jais JP, Venot A, Duclos C. Comparison of two kinds of interface, based on guided navigation or usability principles, for improving the adoption of computerized decision support systems: application to the prescription of antibiotics. J Am Med Inform Assoc 2014 Feb;21(e1):e107-e116 [FREE Full text] [doi: 10.1136/amiajnl-2013-002042] [Medline: 24008427]

41. Duke JD, Li X, Grannis SJ. Data visualization speeds review of potential adverse drug events in patients on multiple medications. J Biomed Inform 2010 Apr;43(2):326-331 [FREE Full text] [doi: 10.1016/j.jbi.2009.12.001] [Medline: 19995616]

42. Warner J, Yang P, Alterovitz G. Automated synthesis and visualization of a chemotherapy treatment regimen network. Stud Health Technol Inform 2013;192:62-66 [FREE Full text] [Medline: 23920516]

43. Smartphone application for antibiotic prescribing. National Centre for Infection Prevention and Management (CIPM) and Imperial College Healthcare NHS Trust. 2013 Jan 04. URL: https://webarchive.nationalarchives.gov.uk/20130104192657/ http://www.dh.gov.uk/health/2012/08/smartphone-antibiotic-prescribing/ [accessed 2021-06-05]

44. Linder JA, Rose AF, Palchuk MB, Chang F, Schnipper JL, Chan JC, et al. Decision support for acute problems: the role of the standardized patient in usability testing. J Biomed Inform 2006 Dec;39(6):648-655 [FREE Full text] [doi: 10.1016/j.jbi.2005.12.002] [Medline: 16442853]

45. Challen R, Denny J, Pitt M, Gompels L, Edwards T, Tsaneva-Atanasova K. Artificial intelligence, bias and clinical safety. BMJ Qual Saf 2019 Mar;28(3):231-237 [FREE Full text] [doi: 10.1136/bmjqs-2018-008370] [Medline: $\underline{\text { 30636200] }}$

46. Esmaeilzadeh P, Sambasivan M, Kumar N, Nezakati H. Adoption of clinical decision support systems in a developing country: Antecedents and outcomes of physician's threat to perceived professional autonomy. Int J Med Inform 2015 Aug;84(8):548-560. [doi: 10.1016/j.ijmedinf.2015.03.007] [Medline: 25920928] 


\section{Abbreviations}

CPG: clinical practice guideline

CDSS: clinical decision support system

GP: general practitioner

VCM: Visualisation des Connaissances Médicales (Visualization of Medical Knowledge)

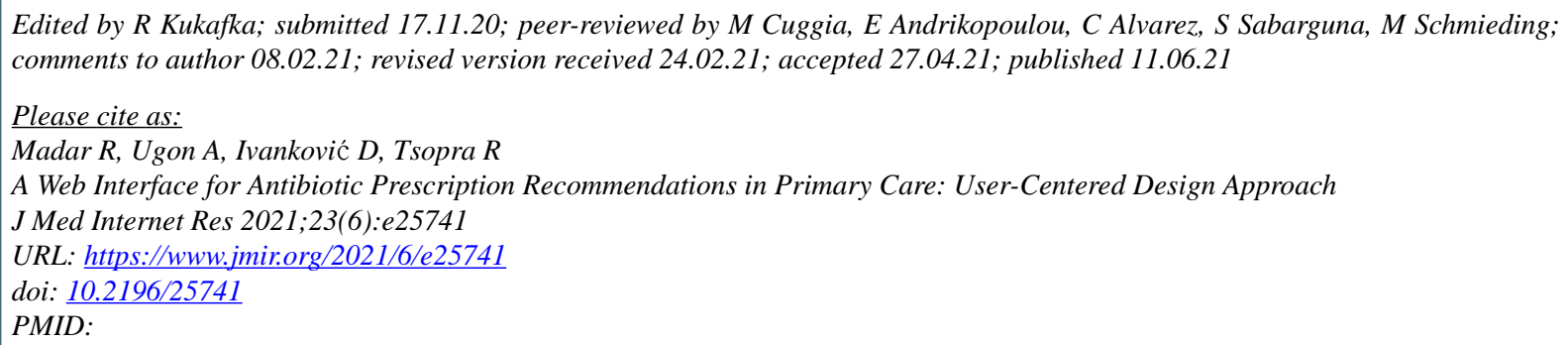

CRonni Madar, Adrien Ugon, Damir Ivanković, Rosy Tsopra. Originally published in the Journal of Medical Internet Research (https://www.jmir.org), 11.06.2021. This is an open-access article distributed under the terms of the Creative Commons Attribution License (https://creativecommons.org/licenses/by/4.0/), which permits unrestricted use, distribution, and reproduction in any medium, provided the original work, first published in the Journal of Medical Internet Research, is properly cited. The complete bibliographic information, a link to the original publication on https://www.jmir.org/, as well as this copyright and license information must be included. 